\title{
Zwischen Phänomenologie des Geistes und Vermögen zum Bösen: Schellings Reaktion auf das Debüt von Hegels System
}

\author{
von Thomas Buchheim (München)
}

\begin{abstract}
By re-evaluating all available sources this paper shows that Hegel's Preface to the Phänomenologie des Geistes, despite his protestations to the contrary, is directed against Schelling's programme Darlegung des wahren Verhältnisses der Naturphilosophie zu der verbesserten Fichteschen Lehre (1806). The hints that Schelling took from Hegel's Preface are followed up to the System der Weltalter (1827). This paper shows, firstly, how Schelling's conception of a system changes from the Freiheitsschrift onwards on the basis of suggestions from Hegel's Phänomenologie; and secondly, how Schelling criticises Hegel at this time. Schelling appropriated fundamental ideas from Hegel to such an extent that he even uses the expression ,Phänomenologie des Geistes' to characterise his own systematic development after his natural philosophy.
\end{abstract}

Die sogenannte ,Entfremdung ${ }^{6}$ zwischen Schelling und Hegel ${ }^{1}$ - nachdem seit Schellings Wechsel von Jena nach Würzburg der briefliche Kontakt zwischen ihnen im Jahr 1804 zunächst aussetzte und trotz eines kurzen Wiederauflebens in der Zeit rund um das Erscheinen von Hegels Phänomenologie des Geistes im Frühwinter 1807 endgültig versiegte - gilt gemeinhin nur als schon zu erwartende Bestätigung einer

\footnotetext{
1 Vgl. die reichhaltige Materialsammlung „Schelling und Hegel. Ihre Entfremdung" von Horst Fuhrmans 1962, 451-553, sowie die ausgewogen urteilende Darstellung von Hermann Krings 1977; ergänzend s. auch Wilhelm G. Jacobs 1998, bes. 79f. Andere Publikationen zum Verhältnis zwischen Schelling und Hegel betreffen entweder allein die erst spät explizit gewordene Kritik Schellings an Hegel (vgl. z. B. Düsing 1977; Theunissen 1977; Horstmann 1986; Frank 1989; Ehrhardt 1992) oder aber beschränken sich auf naturphilosophische Kontexte, die besonders die frühere Zeit beider angeht (z. B. Bonsiepen 1981; Moiso 1986). Dabei entgeht den auf die spätere Zeit konzentrierten Autoren, daß, wie hier gezeigt wird, wichtige Motive von Schellings dann erst explizit werdender Kritik an Hegel, aus der Zeit seiner Auseinandersetzung mit Hegels „Phänomenologie des Geistes" zu stammen scheinen.
}

Archiv f. Gesch. d. Philosophie 85. Bd., S. 304-330

(C) Walter de Gruyter 2003

ISSN 0003-9101 
mittlerweile so unterschiedlich verlaufenen philosophischen Entwicklung2, dass ein Gedankenaustausch zwischen beiden ohnehin nicht mehr fruchtbar für die gegenseitige Anregung hätte sein können.

Eine neue und genauere Betrachtung aller in Frage kommenden Quellen zeigt jedoch mindestens auf der Seite Schellings, dass jenes Wiederaufleben offenbar größere Folgen für seine Systemkonzeption gehabt hat, als bislang vermutet wurde. Es ist nicht nur die - wie zu zeigen sein wird - entgegen äußerlichen Beteuerungen direkt auf Schelling gemünzte harsche Kritik der „Vorrede“ zur Phänomenologie, welche Schelling zu gewissen Konsequenzen veranlasste, sondern es ist die gesamte Konzeption dieses ersten systematischen Auftritts der Hegelschen Philosophie, die ihn dazu bringt, fast so etwas wie eine Kehrtwende in der Methode seiner Systementwicklung einzuleiten.

Man darf indessen nicht hoffen, eine solche These in der Weise belegen zu können, dass Schelling etwa ein offenes Bekenntnis zur Hegelschen Philosophie abgelegt hätte. Vielmehr sind es nur Hinweise und immerhin deutliche Spuren von Veränderungen, die im Einzelnen manchmal anzweifelbar und unsicher bleiben, die aber insgesamt - und zudem gepaart mit erheblicher Gegenkritik an Hegel - eine plausible Erklärung für einen schon immer bemerkten methodischen Wechsel in der Philosophie Schellings nach 1807 anbieten. Dadurch wird in keiner Weise die Eigenständigkeit der Philosophie Schellings in Frage gestellt; vielmehr wird an einem weiteren Beispiel gezeigt, dass die nie erschöpfte Fähigkeit zur Berücksichtigung triftiger Einwände - ohne seine eigenen Hauptanliegen dabei preisgeben zu müssen - eine der wahren Stärken von Schellings Philosophie gewesen ist.

\section{Entdeckung und Ausmaß des Dissenses}

Als Schelling irgendwann im Mai 1807 die längst von Hegel angekündigte Phänomenologie des Geistes erhielt und anfing, die Vorrede zu le$\operatorname{sen}^{3}$, muss er einigermaßen fassungslos und entsetzt gewesen sein. Aber

2 Vgl. etwa Krings 1977, 15f.; 22: „Hegel und Schelling gehen verschiedene Wege. Wenn die Verschiedenheit der philosophischen Denkform nicht jetzt und auch später nicht ein Gegenstand der Diskussion zwischen ihnen geworden ist, so mag dazu wiederum ihre Umgebung und die Parteilichkeit der Anhänger beigetragen haben".

3 Es ist nicht genau bekannt, wann Schelling die Phänomenologie des Geistes erhielt; auch nicht, wann er mindestens die Vorrede gelesen hat. Hegel kündigt ihm die Zusendung des Buches brieflich am 1. 5. 1807 an; Schelling antwortet erst am 2. 11. und bekennt, wegen mannigfaltiger Abhaltungen nur erst die Vorrede gelesen zu haben. Ich halte es für wahrscheinlich, daß Schelling sofort nach 
nicht wie so oft entsetzt über vermeintlichen Unsinn und eine sich erneut bestätigende Seichtigkeit philosophischer Konkurrenten, sondern entsetzt über die Schlagkraft eines völlig unvermuteten Gegners und über das Ausmaß des Dissenses mit ihm - seinem früheren Mitstreiter wie er sich namentlich in der Vorrede auftat.

Schelling hat rasch erkannt, daß und wo eine „Aussöhnung“ ihrer beiden seit der Jenaer Zeit getrennt entwickelten Standpunkte nicht mehr möglich war und höchstens auf eine Entscheidung über Recht- oder Unrechthaben zulief. ${ }^{4}$ In diesem Sinn schreibt er an Hegel Anfang November 1807 einen Brief, mit dem er ihm seine kurz vorher gehaltene Akademierede übersendet, und in dem er sich entschuldigt, wegen dieser und anderer „Abhaltungen“ bislang nicht mehr als die Vorrede gelesen zu haben; einen Brief in einerseits freundschaftlich klingendem, andererseits etwas verzagt sich eben noch selbstbehauptendem Ton, der das letzte sachliche Wort markiert, das zwischen den beiden je noch gewechselt wurde:

Das, worin wir wirklich verschiedener Überzeugung oder Ansicht sein mögen, würde sich zwischen uns ohne Aussöhnung kurz und klar ausfindig machen und entscheiden lassen; denn versöhnen läßt sich freilich Alles, Eines ausgenommen. So bekenne ich, bis jetzt Deinen Sinn nicht zu begreifen, in dem Du den Begriff der Anschauung opponierst. Du kannst unter jenem doch nichts anderes meinen, als was Du und ich Idee genannt haben, deren Natur es eben ist, eine Seite zu haben, von der sie Begriff, und eine, von der sie Anschauung ist. ${ }^{5}$

Doch Hegel konnte sehr wohl etwas völlig anderes mit dem „Begriff“ meinen, als was sich beide früher träumen ließen, was aber nur Schelling und nicht Hegel inzwischen zu weiterer Perfektion und fast zum eigenen Überdruss fortentwickelt hatte. Der Begriff „opponiert“ nach Hegels mittlerweile unumstößlich gewordener Überzeugung nicht nur der Anschauung, sondern er zerstört sie, zerstört nämlich den Schein der Unmittelbarkeit und positiven Gegebenheit des Angeschauten und verwandelt dies in ein bloßes Moment an der Selbstbewegung des negativen und vor allem: reinen, d. h. unanschaulichen Begriffs. Diese Verflüchtigung der Anschauung in die Bewegung des Begriffs bildet bekanntlich den Gesamttenor der Hegelschen Phänomenologie: „indem

Erhalt zum ersten Mal darin las und erst danach sich der Ausarbeitung seiner Akademierede widmete; klare Evidenzen dafür gibt es allerdings nicht, wenn mir auch der Text der Akademierede bereits einen gewissen Einfluß der Hegelschen Vorrede zu verraten scheint (s. u.).

${ }^{4}$ Dass Schelling im nachfolgend zitierten Brief den diagnostizierten Dissens mit Hegel für , unaussöhnbar' hält, wird in der einschlägigen Debatte und auch von Krings 1977, 20f. nicht genügend berücksichtigt.

5 Brief vom 2. 11. 1807 (Hoffmeister I, 194). 
die Wahrheit behauptet wird, an dem Begriffe allein das Element ihrer Existenz zu haben" 6 .

So spricht das Programm des Hegelschen Systems geradezu aus, wovon Schelling ohne Hoffnung auf Aussöhnung sagt, der ihm bekannte Hegel könne es nicht meinen. Doch ist es noch viel schlimmer. Denn Hegel weiß sich mit diesem Programm laut der Vorrede „im Widerspruch mit einer Vorstellung und deren Folgen [...], welche eine so große Anmaßung als Ausbreitung in der Ueberzeugung des Zeitalters hat" (GW 12,5-7; ThW 15). Ich bemerke ausdrücklich, dass der Widerspruch sich sowohl gegen die Vorstellung selbst als auch gegen deren Folgen richtet. Mindestens unter den „Folgen“ sind aber, laut Schellings und Hegels brieflicher Bekräftigung, die damals ungemein zahlreichen Nachredner und Epigonen Schellingscher Naturphilosophie zu verstehen. Indessen scheint, wenn doch für Hegel die „Folgen“ von der „Vorstellung“ zu unterscheiden sind, eben auch letztere das Ziel seiner kritischen Einrede zu sein. Die Kritik soll demzufolge nach Hegels wahrer Auffassung auch den Archegeten der Vorstellung, also Schelling selbst treffen. Was aber ist der Inhalt dieser Vorstellung in Hegels Beschreibung?

Wenn nemlich das Wahre nur in demjenigen oder vielmehr nur als dasjenige existirt, was bald Anschauung, bald unmittelbares Wissen des Absoluten, Religion, das Seyn - nicht im Centrum der göttlichen Liebe, sondern das Seyn desselben selbst - genannt wird, so wird von da aus zugleich für die Darstellung der Philosophie vielmehr das Gegentheil der Form des Begriffs gefodert. Das Absolute soll nicht begriffen, sondern gefühlt und angeschaut, nicht sein Begriff, sondern sein Gefühl und Anschauung sollen das Wort führen und ausgesprochen werden. (GW 12,10-16; ThW 15)

Offenbar nicht zum beiderseitigen Vorteil hatte Schelling Ende des vorangegangenen Jahres - nach längerer Trennung und Schweigen zwischen ihnen wieder Kontakt aufnehmend - seine neueste Schrift gegen Fichte Darlegung des wahren Verhältnisses der Naturphilosophie zu der verbesserten Fichteschen Lehre an Hegel gesandt. Dies geschah von Schelling aus, teils um zu zeigen, dass er Hegels Differenzschrift immer noch schätze und zitiere, teils um ihn über den Stand seiner Ansichten und ein ganz und gar neues Element in seiner Gedankenentwicklung zu

\footnotetext{
${ }^{6}$ Hegel, Phänomenologie des Geistes GW 12,4f. ThW 15. Die Zitate aus der Phänomenologie werden nach Bd. 9 der kritischen Ausgabe in den Gesammelten Werken (GW) zitiert; der leichteren Auffindbarkeit halber wird die Seitenzahl gemäß der Theorie Werkausgabe (ThW) im Suhrkamp-Verlag hinzugefügt.
} 
informieren. Hegel hat diese Schrift nachweislich gut studiert ${ }^{7}$, doch war der Effekt der Lektüre gerade der umgekehrte von dem, den Schelling sich erhofft hatte. Hegel fühlte sich eher befremdet von den auf eine gewisse Spitze getriebenen Ansichten - besonders der Anschauungsseligkeit - seines früheren philosophischen Kompagnons und schien zugleich die neuen Elemente in Schellings Systementwicklung nicht wahrgenommen zu haben. ${ }^{8}$

Wie dem auch sei, Hegel nimmt die Schrift Schellings gerade zu der Zeit (Ende 1806 bis Anfang 1807) zur Kenntnis, in der er die Vorrede zu seiner Phänomenologie verfasst. ${ }^{9}$ Dadurch gerät ihm die Vorrede geradezu wie ein in allen Punkten widersprechender Kommentar zu Schellings neuestem Opusculum, das seinerseits so etwas wie ein programmatisches Manifest Schellingscher Philosophie gegenüber Fichte sein sollte. ${ }^{10}$ Entsprechend unzweideutig und entschieden sind Tonfall und Melodie der dortigen Ausführungen Schellings:

[...] die Wahrheit selbst [ist] das Sein, das Sein oder die Natur selbst die Wahrheit. (SW VII, 109)

7 Hegel geht auf sie im Ganzen ein in seinem Dankesbrief an Schelling vom 3.1. 1807; dort diagnostiziert er auch ihren weniger polemischen, als vielmehr für Schellings Philosophie durchaus programmatischen Charakter: „Der Zweck der Schrift, der außer der notwendigen Erklärung über die letztere Seite [gemeint sind gewisse „Niederträchtigkeiten“ Fichtes] sich auf das eigentlich Philosophische einschränkt, macht, daß Du dies neuerliche Auftreten Fichte's noch schonend behandelt hast" (Hoffmeister I, 131). Zusätzlich erwähnt Hegel eine eher entlegene Einzelheit aus Schellings Schrift auch noch einmal in seinem vorletzten Brief an Schelling vom 23.2.1807 (Hoffmeister I, 151).

8 Vgl. Fn. 17.

9 Hegel an Schelling am 3.1.1807: „Bei meiner Rückkunft aus Bamberg, wo ich einige Wochen zugebracht habe [etwa vom 10.11. bis 15.12.] fand ich - vor etwa 14 Tagen, - Deine Schrift, das Verhältnis der Naturphilosophie zur neuverbesserten Fichte'schen betreffend, hier vor" (Hoffmeister I, 130). Hegel hatte in Bamberg, ein Zimmer in der Nähe von Niethammers bewohnend und dort in Kost, den Druck der Phänomenologie durch die Göbhardtsche Druckerei - nach vielen diesbezüglichen Irritationen im Vorfeld - persönlich überwacht. Allein die „Vorrede“ zur Phänomenologie war zu dieser Zeit noch gar nicht fertig oder nicht einmal begonnen. Denn erst am Freitag, den 16. Januar schreibt Hegel wiederum von Jena aus an Niethammer: „Ihren letzten Brief, wertester Freund, den ich um der Rekommendation auf der Adresse willen Sonnabends früh statt Mittags erhalten, habe ich damit honoriert, daß ich denselben Tag Manuskript der Vorrede an Göbhardt geschickt [...] " (Hoffmeister I, 136). Das müßte also Samstag, der 10.1.1807 gewesen sein oder allenfalls der 3.1. - jedenfalls nach der Lektüre von Schellings Schrift.

10 Die in Fn. 1 genannten Autoren gehen so gut wie nicht auf diese frühere Zusendung Schellings an Hegel ein (vgl. allein Fuhrmans 1962, 522f.) und bemerken daher auch nicht, in welchem Maß und mit welcher Genauigkeit die Vorrede der Phänomenologie Schellings Philosophieprogramm widerspricht. 
Was ist der wahre Geist des Naturforschers? - Er ist Andacht, Frömmigkeit gegen die Natur, Religion, unbedingte Unterwerfung unter die Wirklichkeit und die Wahrheit, wie sie in der Natur ausgesprochen und mit der Natur selbst eins ist. (SW VII, 109)

Wir haben behauptet, und behaupten als eine bewiesene Sache, daß die Welt als ungebrochen und farblos nicht nur zu denken, sondern in der Tat zu schauen ist und wirklich geschaut wird; so wie wir auch in der Farbe nicht eigentlich die Finsternis, sondern eben das Licht sehen, und nur mittelst desselben sein Gegenteil bemerken; wir behaupten, daß das Göttliche in der Natur keineswegs verhüllt und unsichtbar, lediglich in Gedanken zu fassen, sondern daß es offenbar, anschaulich, gegenwärtig, das eigentlich Unmittelbare ist, so wie dagegen alles Ungöttliche das bloß Mittelbare, lediglich zu Erdenkende; wir behaupten, daß es uns unmöglich ist auch nur irgend einen Teil der Materie nicht als Leben zu begreifen, so wie daß es nur von jedem selbst abhängt, in der Zeit selbst die Ewigkeit als wirklich zu sehen, und sonach im wirklichen Bewußtsein die Zeit los zu werden. (SW VII, 95f.)

Die Naturphilosophie stellt in der Natur unmittelbar das Positive dar, ohne Rücksicht auf das andere, z. B. den Raum und das übrige Nichtige. So sieht sie in dem Magnet nichts anderes als das lebendige Gesetz der Identität; das im Raum ausgesprochene, aber auf keine Weise von ihm getrübte, $\mathrm{A}=\mathrm{A}$. Ebenso erkennt sie in dem Körper nur die entfaltete Copula, als Schwere, als Cohäsion u.s.w.; den Körper selbst aber lediglich als das Gefaßte dieses entfalteten Bandes, das ohne dieses in nichts zerfiele. (SW VII, 64)

Du schaust, auch ohne daß du es weißt und willst, ewig nur die Einheit des Verbundenen mit dem Band, d.h. das Band selbst an; alles Übrige aber magst du bloß denken oder imaginieren, keineswegs aber in Wahrheit erblicken. (SW VII, 60)

Es finden sich in dieser Schrift Schellings also genau die Dinge von Farblosigkeit, inbrünstiger Anschauung und Unmittelbarkeit des eintönigen Wahren sowie die Nichtberücksichtigung jeglichen Details, die Hegel in seiner Vorrede an den Pranger stellt.

Der Dissens geht aber noch weiter, als diese wenigen und kurzen Zitate auf beiden Seiten belegen können. Er ist geradezu, und das ist in der Philosophie schließlich nichts Unerhörtes, ein Dissens auf Leben und Tod. Denn was Schelling in jener Schrift als Sehen des „Todes“ und als „Todesschlaf" des bloßen Denkens statt Anschauen des Lebens in der Gottinnigkeit und wahren Religion des echten „Physikers" brandmarkt, eben das muss nach Hegel der Begriff erst erzeugen, um im Durchgang dadurch und Aushalten davon zum Leben des Geistes zu gelangen. So schreibt Schelling beispielsweise:

Was begehrt der Physiker? Das Leben, und nur dieses ist die Beute, die er aus dem Kampf mit dem Tode davontragen will. - Die Fichtesche Theorie zieht ihm hier eine absolute Grenze vor, jenen Schlag des absoluten Bewußtseins, der unwiederbringlich für jede wirkliche Anschauung das Leben in Tod verwandelt und die leere Hülle allein zur Betrachtung übrig läßt. (SW VII, 109f.) 
[...] wie es mit der Anschauung des Lebendigen ins Unendliche gehen kann, so daß sich der Punkt, bei welchem sie noch ankommen mag, gar nicht bestimmen und gar nicht voraussehen läßt, in welchem Grade die mittelbare Erkenntnis, die doch nur das Surrogat der ermangelnden unmittelbaren ist, verschwinden werde so kann es auch mit der Ansicht und dem endlich wirklichen Sehen des Todes ins Unendliche gehen. (SW VII, 93f.)

[...] die Gelehrten [haben] durch ihre Meinungen den Tod wieder eingeführt und ihre die Natur mechanisch verkehrenden Systeme über den lebendigen Grund der Natur selbst gesetzt, zu einem bloß historischen Glauben im Wort und nicht im Geist, im Begriff und nicht in der Anschauung. (VII, 115)

Dagegen lässt sich Hegel vernehmen:

Aber daß das von seinem Umfange getrennte Accidentelle als solches, das gebundne [= das nichtige „Verbundene“ des Bandes bei Schelling] und nur in seinem Zusammenhange mit anderm Wirkliche ein eigenes Daseyn und abgesonderte Freyheit gewinnt, ist die ungeheure Macht des Negativen [Schelling beschwört demgegenüber ausschließlich das „Positive“]; es ist die Energie des Denkens, des reinen Ichs. Der Tod, wenn wir jene Unwirklichkeit so nennen wollen, ist das furchtbarste, und das Todte fest zu halten, das, was die größte Krafft erfodert. [...] nicht das Leben, das sich vor dem Tode scheut [...], sondern das ihn erträgt und in ihm sich erhält, ist das Leben des Geistes. [...] Diese Macht ist er nicht, als das Positive, welches von dem Negativen wegsieht [...]; sondern er ist diese Macht nur, indem er dem Negativen ins Angesicht schaut, bey ihm verweilt. Dieses Verweilen ist die Zauberkraft, die es in das Seyn umkehrt. (GW 27, 21-35; ThW 36)

Und noch einmal Schelling, der umgekehrt gerade das Denken des Besonderen verurteilt, weil es wegsieht vom Positiven und den Glauben erzeugt, dass das Negative wirklich sei:

[...] das Viele als das Viele ist auf keine Weise sichtbar; denn es wird gesehen, nur insofern es beleuchtet ist von dem Einen, d.h. nur sofern es nicht Vieles ist. Als Vieles kannst du es nur denken und es ist als solches lediglich dein Denken, keineswegs aber das Wirkliche oder das Sein, welches nur Eines ist. [...] es liegt bloß an dir selbst, wenn du nicht das Positive des Vielen und eben darum es selbst als Eines zu sehen glaubst. [...] [J]enes Denken [ist] wesentlich ein Absehen von dem Reellen. (SW VII, 60f.)

Für jemanden, der Schellings Philosophie schätzt, ist es geradezu schmerzlich zu sehen, wie unmittelbar, direkt und offen mit wörtlichen Anspielungen auf die gelesene Schrift Hegel Schellings philosophische Grundsätze demontiert und verneint. Das was Schelling dort die „Ungereimtheit aller Ungereimtheiten“ nennt, nämlich das „sich selbst entfremdet werden" des Absoluten als Geist oder Leben (SW VII, 57), eben das ist es, was Hegel zum Motor seiner spekulativen Philosophie einsetzt. 


\section{Schellings erste Reaktionen}

Schellings philosophische Entwicklung bis zum Jahr 1806 hat nicht nur vielen anderen Zeitgenossen missfallen (woran Schelling gewöhnt war), sondern hat, wie Schelling nun dämmert, offenbar auch Hegel zutiefst abgestoßen. Doch ist es bemerkenswert, dass nun wiederum Schelling derjenige ist und weiterhin sein wird, der in seinem eigenen Denken solche Selbstentfremdungen durchmacht und aushält, wie Hegel sie fordert; der lernt von der Negativität des Hegelschen Begriffs und sich dadurch weiter entwickelt, während Hegel nichts, aber auch gar nichts von seinem ehemals gepriesenen Mitphilosophen und Freund mehr annehmen möchte. Schellings Philosophie versucht immer wieder das Andere ihrer selbst zu berücksichtigen und einzubauen - ob es nun Fichte oder Hegel oder Jacobi hieß. Während Hegels Philosophie, einmal gefasst, nur noch ihren spekulativen Rhythmus selbstbezüglicher Negativität exekutiert.

Aus diesem bis ins Persönliche reichenden Unterschied zwischen beiden speist sich auch ein Gutteil von Schellings Kritik an Hegel, die zunächst schwer zu entdecken, später aber immer lauter zum Vortrag kommt: Dass Hegel nämlich unfähig sei, etwas Positives, Gegebenes, Wirkliches außer seinem Denken übrig zu lassen, das eine unerledigte Aufgabe darstellen könnte, der das Denken durch Veränderung und Anpassung seiner selbst erst noch gerecht zu werden hätte. Was nichts anderes heißt, als dass Hegels Denken unfähig sei zur positiven Philosophie.

Dagegen ist Schelling stets in der Lage gewesen und geblieben, trotz seiner für manche unangenehmen, von sich selbst überzeugten und brusttönenden Art, das Unerledigte, neu sich Auftuende und Widerstand Leistende durch seine Philosophie wahr- und in Angriff zu nehmen.11 Schellings Denken besitzt sozusagen eine besonders hohe ,Irritabilität‘.

So auch schon 1807, als er zuerst Hegels Phänomenologie des Geistes, mindestens aber die Vorrede las und ihn das schon erwähnte Entsetzen packte, das sich eben nicht nur auf Hegel, sondern in mancher Hinsicht auf seine eigene Philosophie bezog. ${ }^{12}$ In seiner berühmten Akademierede Über das Verhältnis der bildenden Künste

11 Symptomatisch dafür ist ein eindrucksvoller Satz aus seiner späten Kritik an Hegel: ,Wirkliches Denken ist, wodurch ein dem Denken Entgegenstehendes überwunden wird" (SW X, 141).

12 Ehrhardt 1992, bes. 14f. weist auf einige wenig bekannte Passagen aus Schellings Einleitung in die Philosophie (gemeint ist die Abschrift eines Studienhefts für Maximilian II. von Bayern, die Ehrhardt 1989 publiziert hat) hin, in denen Schelling klar bekennt, durch Hegels Philosophie erst auf gewisse „Schranken“ seiner eigenen Naturphilosophie aufmerksam geworden zu sein. 
$z u$ der Natur aus demselben Jahr sucht man überraschender Weise nach dem Wort und der Sache einer uns ursprünglich möglichen Anschauung der Dinge an sich oder des Göttlichen oder des Einen und Ganzen vergeblich. Die Anschauung kommt überhaupt kein einziges Mal auf signifikante Weise vor - für eine Rede über die Kunst schon selbst ein kleines Kunststück.

Statt dessen liest man anderes, was einen unwillkürlich an Hegels Vorhaltungen und eine beginnende Auseinandersetzung mit ihnen erinnert:

[...] die meisten [betrachten] das Einzelne verneinend, nämlich als das, was nicht das Ganze oder Alles ist: es bestehet aber kein Einzelnes durch seine Begrenzung, sondern durch die ihm einwohnende Kraft, mit der es sich als ein eignes Ganzes dem Ganzen gegenüber behauptet. Da diese Kraft der Einzelheit und also auch der Individualität sich als lebendiger Charakter darstellt, so hat der verneinende Begriff derselben notwendig die ungenügende und falsche Ansicht des Charakteristischen in der Kunst zur Folge. [...] Wir verlangen allerdings nicht das Individuum, wir verlangen mehr zu sehen, den lebendigen Begriff desselben. [...] Die Natur $[\ldots]$ sehen wir in allem Einzelnen auf Bestimmtheit, ja zuerst und vor allem andern auf Härte, auf Verschlossenheit des Lebens hinwirken. Wie die ganze Schöpfung ein Werk der höchsten Entäußerung ist ${ }^{13}$, so muß der Künstler zuerst sich selbst verleugnen und ins Einzelne hinabsteigen, die Abgeschiedenheit nicht scheuend, noch den Schmerz, ja die Pein der Form. [...] Nur durch die Vollendung der Form kann die Form vernichtet werden, und dieses ist allerdings im Charakteristischen das letzte Ziel der Kunst. (SW VII, 303-305)

Wer den Text von Hegels Vorrede kennt, entdeckt hier unschwer (neben Böhmischen Einsprengseln) den Hegelschen Duktus der Gedanken und Hegels Forderung wieder ${ }^{14}$, sich die Form und Arbeit am Begriff des Einzelnen über dem Wesen der Sache nicht zu ersparen. ${ }^{15}$ Allerdings ist es nicht nur dies, nicht nur die durch das Einzelne hindurchgehende Negativität, welche für Schelling am Ende als das Positive und das Wesen heraustritt, sondern es ist zwar das Negative der Weg und das Verfahren, welches aber ein anderes Positives - den „lebendigen Charakter“ von etwas - aus der

13 Der Gedanke einer „Entäußerung“ hier zum ersten Mal bei Schelling - Hegel gebraucht ihn geradezu inflationär, vor allem am Ende der Phänomenologie.

14 Einige Beispiele für verwandt Klingendes aus der Vorrede Hegels: „,[D]iese Idee [vom Leben Gottes als der Bestimmung des Ganzen] sinkt zur Erbaulichkeit und selbst zur Fadheit herab, wenn der Ernst, der Schmerz, die Geduld und Arbeit des Negativen darin fehlt. [...] Wenn die Form als dem Wesen gleich ausgesagt wird, so ist es ebendarum ein Mißverstand zu meynen, daß das Erkennen sich mit dem Ansich oder dem Wesen begnügen, die Form aber ersparen könne" (GW 18,30-19,5; ThW 24); erfordert ist, ,,sich dem Leben des Gegenstandes zu übergeben [...] Sich so in seinen Gegenstand vertieffend, vergißt es jeder Uebersicht [...] Aber in die Materie versenkt und in deren Bewegung fortgehend, kommt es in sich selbst zurück" (GW 39,9-14; ThW 52).

15 Dieser Grund einer schon sehr früh einsetzenden Kritik Hegels an Schelling noch während der Konzeption einer eigenen Naturphilosophie seit 1803 wird in akribischer Untersuchung sehr überzeugend aufgedeckt von Moiso 1986. 
Verschlossenheit im Einzelnen befreit. Dies Andere und Positive gegenüber dem Negativen, das Hegels Begriff nicht mehr kennen zu müssen vorgibt, ist und bleibt für Schelling der leitende Anspruch, unter dem das Werk der Kunst nach dem oben Zitierten ebenso wie sein Philosophieren im Allgemeinen steht, und das zu ignorieren er schon hier anfängt, Hegel vorzuwerfen.

Wir stellen also fest: Bei Schelling beginnt die Kritik Hegels Wirkung zu zeigen, und er nimmt bereits gewisse Änderungen vor, ohne freilich seine eigenen Hauptpunkte preiszugeben. Hegel dagegen merkt von alledem nichts und betreibt das Mühlrad seines rein negativen Begriffs, ohne von Schelling Notiz zu nehmen, weiter. Schelling schickt nämlich seine Akademierede zusammen mit der eingangs zitierten Stellungnahme zur Vorrede der Phänomenologie an Hegel und bittet ihn seinerseits um ein Urteil über sie. Doch hat Hegel nie auf den Brief geantwortet, wie er übrigens auch in jener früheren Schrift Schellings gegen Fichte, wie schon erwähnt, niemals das Neue gesehen zu haben scheint, das den Schelling der Jenaer Zeit von dem der Münchner Zeit gravierend unterschied. ${ }^{16}$ Dieses Neue war die Entdeckung, dass die Form der bloßen Reflexion oder sich selbst bewusst machenden „Selbstbejahung" und so Verdopplung eines Wesens niemals ausreichen könne, um eine echte „Manifestation“ oder „Offenbarung" von ihm zu denken und begrifflich ins Werk zu setzen; sondern dass man dafür einen ursprünglich besonderen Gehalt, eine Bestimmung oder ein So-Sein von demjenigen braucht, das sich geltend machen oder manifestieren soll; etwas, das also nicht das sich Manifestierende selbst, sondern ein $\mathrm{An}$ deres an oder von ihm sei. ${ }^{17}$ Dieser besondere Gehalt ist es, den Schelling als ,lebendige Natur“" (bereits in der Darlegung gegen Fichte) oder

16 Für Näheres hierzu s. die Einleitung in die von mir veranstalteten Ausgabe der Freiheitsschrift (Schelling 1997, XIIIff.)

17 Vgl. Darlegung des wahren Verhältnisses der Naturphilosophie zu der verbesserten Fichteschen Lehre (weiterhin zitiert als Darlegung). Schelling kritisiert dort die von ihm selbst bis dato vertretene Position explizit: „Wir haben Sein und Erkennen auch entgegengestellt als Wesen und Form; allein auch so ist noch kein wahrer Gegensatz gegeben, denn das Positive in der Form ist selbst nur das Wesen oder das Sein; und die Selbstbejahung ist so weit noch selbst als bloße reine Identität begriffen. Erst mit dieser Indifferenz von Wesen und Form ist auch der Gegensatz; aber sie selbst, die Indifferenz, enthält noch keinen; [...] Wie gelangen wir zu diesem Gegensatz? - Eben nur durch die notwendige Folge der Selbstoffenbarung [...] es offenbart sich aber nicht, wenn es bloß es selbst, wenn es nicht in ihm selbst ein Anderes, und in diesem Anderen sich selbst das Eine, also wenn es nicht überhaupt das lebendige Band von sich selbst und einem Anderen ist." (SW VII, 54). 
als „Charakteristik“ (in der Akademierede) bezeichnet. Während demgegenüber Hegel nie aufhören wird, dieses Andere durch die reflexive Negativität des Begriffs allein gewährleistet zu sehen.

\section{Freiheitsschrift und Phänomenologie des Geistes}

Die Freiheitsschrift ist der nächste relativ einsam stehende Stützpunkt in Schellings philosophischem Schaffen während der Zeit, für die es seine Reaktion auf Hegels Phänomenologie des Geistes und besonders (aber nicht nur) die Vorrede zu beurteilen gilt. M.E. erkennt man an ihr sowohl, wie entschlossen Schelling seine philosophische Errungenschaft - nämlich die zur Manifestation nötige Charakteristik oder Natur des Absoluten - gegen Hegel festhält, als auch, wie geradezu umstürzend und selbstverleugnend er gewisse konzeptionelle Einsichten aus Hegels Vorrede und der Phänomenologie des Geistes überhaupt aufgreift und seiner eigenen Gedankenentwicklung einverleibt.

Wiederum ist es zunächst die Anschauung, die sich in der Freiheitsschrift durch völliges Unterlassenwerden hervortut. „Gott", so sagt Schelling an einer Stelle, „schaut die Dinge an sich an"18. Aber damit hat es sich auch schon; und dies wissen wir im Übrigen spätestens seit Kants Kritik der reinen Vernunft. Was aber ist mit den Menschen, wenigstens den besten, den Philosophen nach Schellings Ansicht, und was mit Schelling selbst? Sie schauen zunächst einmal gar nichts an, sondern kümmern sich laut Freiheitsschrift um ihr Handeln und die Entscheidung zwischen dem Guten und dem Bösen. Allerdings brächte, wie Schelling an einer anderen Stelle bemerkt ${ }^{19}$, eine vollendete Entscheidung des Menschen für das Gute eine „göttliche Magie“ in ihm zum Tragen, durch welche „die unmittelbare Gegenwart des Seienden im Bewußtsein und der Erkenntnis" gegeben sein würde - also genau dasjenige, was Schelling noch in der Darlegung gegen Fichte als den Ausgangspunkt seiner Naturphilosophie verteidigt hatte. Wer aber wiederum weiß, dass nach Schellings Freiheitsschrift der Mensch vorerst nicht zum Guten entschieden ist, sondern vielmehr, so weit an ihm liegt, zum Gegenteil, der weiß auch, dass Schelling selbst jene Magie, die er in der Darlegung noch besa $\beta^{20}$, inzwischen abhanden gekommen sein muss.

18 SW VII, 347; Bu 20,5; die jeweils zweite Seitenangabe mit Zeilenzahl bezieht sich auf die in Fn. 16 erwähnte Ausgabe der Freiheitsschrift.

19 SW VII, 341; Bu 63,24ff.

20 Vgl. Darlegung SW VII, 62: „die ursprüngliche Einfalt des Sehens und des Sinnes, welcher selbst nur die unmittelbare, gleichsam magische Empfindung des Innern und Positiven und das Band deines eignen Wesens mit demselben ist". 
Was Schelling nun vielmehr meint, ist, dass die göttliche Magie in uns und unserem Wissen, solange eine Entscheidung zum Guten nicht vollendet ist, zwar als eine Möglichkeit schlummert, aber wie verdunkelt und umwölkt bleibt von Irrtum und Irritation, jener, wie Schelling den Sachverhalt bezeichnet, „Imagination“ des Nichtseienden und Unwahren, das leider von unserem endlichen Dasein nicht wegzudenken ist. ${ }^{21}$ Ebenso evident ist jedoch auch, dass die Freiheitsschrift den Gedanken der menschlichen Entscheidung zum Guten über den gegenwärtigen Zustand des Menschengeschlechts hinausführt und eine $\mathrm{Zu}$ kunft antizipiert, in der die Vollendung so oder so (durch des Menschen eigene Kraft oder dank göttlicher Hilfe) erreicht sein wird und also auch die „göttliche Magie“ in unserem Wissen wenigstens als ein entferntes Ideal und in bestimmten ihrer Voraussetzungen sich abzeichnet. Dies ist dann das Ende der Freiheitsschrift: die Einkehr des Menschen in die göttliche „Liebe“ alias „Indifferenz"22, in welcher menschliche Wissenschaft und göttliches Selbstbewusstsein in Form eines absoluten Wissens vereinigt sein würden. Die Voraussetzung davon aber ist schon jetzt nach Schelling, d.h. in der noch bösen Gegenwart, dass in uns - wenn auch verdunkelter Weise - ein Unterpfand der göttlichen Liebe und eine geheime Orientierung auf jenes göttliche Wissen vorhanden ist, welches Schelling auf der letzten Seite der Freiheitsschrift als „die Vernunft" namhaft macht:

Die Vernunft ist in dem Menschen das, was nach den Mystikern das Primum passivum in Gott oder die anfängliche Weisheit ist, in der alle Dinge beisammen und doch gesondert, Eins und doch jedes frei in seiner Art sind. Sie [die Vernunft] ist nicht Tätigkeit, wie der Geist, nicht absolute Identität beider Prinzipien der Erkenntnis, sondern die Indifferenz; das Maß und gleichsam der allgemeine Ort der Wahrheit, die ruhige Stätte, darin die ursprüngliche Weisheit [d.i. die Gottes] empfangen wird, nach welcher, als dem Urbild hinblickend, der Verstand bilden soll. (SW VII, 415; Bu 86,20ff.)

In diesem Gedanken Schellings, der fortan ein Hauptgedanke seiner Philosophie sein wird, vereinigt sich ein beträchtliches Maß an Zustimmung zu Hegels Phänomenologie des Geistes mit Schellings entschiedener Kritik an Hegel.

${ }_{21} \mathrm{Zu}$ diesem Grundsachverhalt beim späteren Schelling vgl. Weltalter, 4f.

22 Genauer betrachtet ist die vollendete Liebe als das letztes Ergebnis der Weltentwicklung „Indifferenz" nicht mehr im gleichen Sinne wie am Anfang: ist sie vor dem Beginn nämlich „Gleichgültigkeit“, so ist sie nach ihrem Abschluss die „,allgemeine, gegen alles gleiche und doch von nichts ergriffene Einheit, das von allem freie und doch alles durchwirkende Wohltun, mit Einem Wort, die Liebe“ (SW VII, 408; Bu 80,15-20). Vgl. zu diesem Unterschied Ehrhardt 1995, 228f. 
Die Zustimmung besteht darin, daß die Menschen zunächst nicht über den Standpunkt des absoluten Wissens oder der göttlichen Weisheit verfügen, sondern nur eine Art Kompaß oder eine Ortschaft und Orientierung besitzen, kraft der sie das Wahre vom Falschen im Einzelnen unterscheiden und so die Richtung auf Wahrheit und Wissenschaft einhalten können. Dies nämlich gewährleistet die „Vernunft im Menschen". Und sogar dieses Ortes können wir erst versichert sein, nachdem wir uns in eine Lage des Denkens gebracht haben, in der wir gerechtfertigter Weise annehmen, daß echte Wissenschaft für uns wenigstens möglich ist. Diese Vergewisserung der Möglichkeit echter Wissenschaft ist, wie Hegel deutlich machte, am Ende seiner Phänomenologie des Geistes erreicht. In der Vorrede schrieb er:

[...] das Individuum hat das Recht zu fodern, daß die Wissenschaft ihm die Leiter wenigstens zu diesem Standpunkte reiche. (GW 23,3f. ThW 29)

[...] Diß Werden der Wissenschaft überhaupt, oder des Wissens, ist es, was diese Phänomenologie ${ }^{23}$ des Geistes [...] darstellt. (GW 24,1f. ThW 31)

Wir finden also in der Freiheitsschrift etwas, das Schelling in seiner vorangegangenen identitätsphilosophischen Phase niemals getan hatte: aufzuzeigen, wie und mit welcher Rechtfertigung wir philosophisches, d.h. das Wissen der Weisheit als legitimes Ziel unserer Bemühungen überhaupt in Anspruch nehmen können. Die Freiheitsschrift ist - so könnte man meine These etwas überspitzt formulieren - Schellings Phänomenologie des Geistes.

Einigermaßen hochtrabend tönt uns dagegen der Anfang der Urkunde von Schellings Identitätsphilosophie im Ohr, nämlich die Darstellung meines Systems der Philosophie von 1801, wo Schelling schrieb und es bis 1806 auch immer so gehalten hatte: „mit der gegenwärtigen Darstellung befinde ich mich im Indifferenzpunkt, in welchem nur der recht fest und sicher sich stellen kann, der ihn zuvor von ganz entgegengesetzten Richtungen her konstruiert hat" (SW IV,108). Sechs Jahre lang gingen sämtliche Schriften Schellings von diesem Standpunkt als Prinzip des Wissens aus. Die Freiheitsschrift geht zum ersten Mal nicht mehr von ihm aus, sondern führt zu ihm hin, um dort zu enden. Ihr letzter Satz sagt aus, dass der gegenwärtigen Abhandlung eine Reihe anderer folgen werde, in denen das Ganze des ideellen Teils der Philosophie dargestellt wird. Daraus folgt, wenn nicht, daß die Freiheitsschrift selbst kein Teil dieses Ganzen ist, so doch wenigstens, dass sie nur ein erster Schritt und nicht das ganze System nach seiner ideellen Seite betrachtet sein kann. Sie ist nur eine ,Phänomenologie des Geistes` im von Hegel definierten und geforderten Sinn.

23 Das Wort „Phänomenologie“ hebt Hegel eben deshalb hervor, weil es sich nicht um eine Wissenschaft handelt, sondern der Gegenstand nur im Schein, dem Phänomen seiner Entstehung aufgezeigt wird. 


\section{Kritik der taumelnden Dialektik}

Aber auch deutlich vernehmbare Kritik an Hegel fehlt nicht in der Freiheitsschrift, anzuknüpfen gerade an dem zuletzt angeführten längeren Zitat über die „Vernunft" im Menschen. Denn nach Hegels Vorrede ist die Vernunft alles andere als eine „ruhige Stätte“ und nicht ein in uns gelegtes „Maß der Wahrheit“ und keinesfalls „nicht Tätigkeit“, sondern im Gegenteil pure Tätigkeit, reine „Selbstbewegung“ oder „Werden“ des Begriffs. ${ }^{24}$ Wenn Hegel an einer weiteren Stelle „die Vernunft das zweckmäßige Tun" 25 nennt, so fragt man sich mit vollem Recht, welchen Zweck sie denn nach Hegel verfolgt und woraufhin sie orientiert sei bei all ihrem Tun und negativen Selbstbewegen. Dieselbe Frage hat sich wohl auch Schelling gestellt und als Antwort nur das gefunden, womit auch er - Schelling - die Vernunft in Verbindung sah, nämlich die „Wahrheit“ oder das Wahre; jedoch ganz anders als bei ihm (Schelling):

Das Wahre ist so der bachantische Taumel, an dem kein Glied nicht trunken ist; und weil jedes, indem es sich absondert, ebenso unmittelbar auflößt, - ist er [der Taumel] ebenso die durchsichtige und einfache Ruhe. (GW 35,5-7; ThW 46)

Auch wenn sich keine weiteren Evidenzen dafür aufbieten lassen und im Umkreis zu den diesbezüglichen Überlegungen Schellings einige konkurrierende Bezüge zu anderen Autoren in Frage kommen ${ }^{26}$, entspricht dies doch ziemlich genau demjenigen, was Schelling in derselben Schlusspassage seiner Freiheitsschrift, aus der das Zitat über die Vernunft stammt, so auf einen gegnerischen Nenner gebracht hat:

Wenn, nach den trefflichen Ansichten Franz Baaders, der Erkenntnistrieb die größte Analogie mit dem Zeugungstrieb hat, so gibt es auch in der Erkenntnis etwas der Zucht und Verschämtheit Analoges, und dagegen auch eine Un-Zucht

24 Vgl. GW 40,27; 30; ThW 54.

25 Vgl. GW 20,11f. ThW 26.

26 Besonders Friedrich Schlegel hatte sich in seinem bekannten Indierbuch und einer Fichte-Rezension gegen dialektische und begriffliche Methoden in der Philosophie erklärt; ähnlich hatte Friedrich Heinrich Jacobi in einer Akademierede Über gelehrte Gesellschaften die historische Einsicht als wahre Basis des philosophischen Denkens gepriesen. Beide firmieren auch sonst als die von Schelling speziell ins Auge gefassten Gegner gewisser Grundthesen der Freiheitsschrift. Jedoch ist es für Schelling durchaus möglich, dass sich, je verschwiegener der Name eines Opponenten in seinen Schriften ist, um so triftiger manche Bezüge auf ihn richten; so taucht bspw. der Name Jacobis in der Freiheitsschrift nicht ein einziges Mal auf. Zu weiteren Einzelheiten vgl. die Anmerkungen in der oben genannten Ausgabe der Freiheitsschrift. 
und Schamlosigkeit, eine Art faunischer Lust, die an allem herumkostet, ohne Ernst und ohne Liebe, etwas zu bilden oder zu gestalten. (SW VII, 414; Bu 85,33-86,5)

Sollte diese Bemerkung Hegel gelten, dann lautet Schellings Diagnose offenbar so, dass Hegel, nachdem er seinerseits die Leere und Gestaltlosigkeit der früheren Naturphilosophie gegeißelt hatte, nunmehr dank einer rein negativ bleibenden Dialektik selbst außerstande ist, etwas Bleibendes und Bestimmtes zu erzeugen, d.h. ihm in klar ausgerichteten Thesen eindeutige Gestalt und Umrisse zu geben; daß er statt dessen alles und zugleich dessen Gegenteil - voll faunischer oder bacchantischer Lust - alsbald in die gestaltlose Ruhe seiner Negativität wieder einebnet. ${ }^{27}$ Oder welchen Begriff, welche Idee könnte man anführen, die Hegels spekulativen Gedankengang mit festen Umrissen überstehen würde?

Fasst man Schellings Monitum zusammen und bezieht es auf Hegel, so wäre die Dialektik Hegels also eine unvollständige und nur vorläufige, zwar messerscharf unterscheidende, aber insgesamt völlig orientierungslose und darum nichts auf bleibende Weise gestaltende oder erzeugende Dialektik. Das bloße Unterscheiden läuft nach Schelling leer, wenn es nichts hat, worauf es hinauswill. Schelling dagegen war überzeugt, wirklich etwas zum Ziel zu haben, worauf er mit seiner Dialektik hinauswollte: die positive Bestimmtheit oder Natur Gottes als des Absoluten. „Die Philosophie“, so schreibt er wiederum in derselben Schlusspassage der Freiheitsschrift, „hat ihren Namen einerseits von der Liebe, als dem allgemein begeisternden Prinzip, andererseits von dieser ursprünglichen Weisheit, die ihr eigentliches Ziel ist" (SW VII, 415; Bu 86,28). Hat sie hingegen kein Ziel mehr, dann hilft auch ein faunisch-bacchantischer Taumel der Begeisterung nichts, in den manche die philosophische Erkenntnis versetzen wollen; sondern dann kommt ihr, so sagt Schelling, zugleich der ordnende und gestaltende Verstand mit dem Maß der ursprünglichen Vernunft abhanden:

Wenn der Philosophie das dialektische Prinzip, d.h. der sondernde, aber eben darum organisch ordnende und gestaltende Verstand, zugleich mit dem Urbild, nach dem er sich richtet [als dem Ziel der göttlichen Weisheit], entzogen wird, so, daß sie [die Philosophie] in sich selbst weder Maß noch Regel mehr hat: so bleibt ihr allerdings nichts anderes übrig, als daß sie sich historisch zu orientieren sucht, und die Überlieferung, an welche bei einem gleichen Resultat schon früher verwiesen worden, zur Quelle und Richtschnur nimmt. (SW VII, 415; Bu 86f.)

27 Nicht unähnlich beschreibt Schelling - halb bewundernd und halb verurteilend Hegels Philosophiestil in einem Brief an Schubert vom 27.5.1809 (Fuhrmans 1975, Bd. III, 610): „Ein solches Exemplar innerlicher u. äußerlicher Prosa muß in unsern überpoetischen Zeiten heilig gehalten werden. Uns alle wandelt da u. dort Sentimentalität an; dagegen ist ein solcher verneinender Geist ein treffliches Correctiv, wie er im Gegenteil belustigend wird, sobald er sich übers Negieren versteigt". 
Was mich bestärkt, hierin eine Kritik an Hegel zu erkennen, ist erstens, dass Hegel in seiner Vorrede und überwiegend auch in der Phänomenologie selbst genau so vorgeht, dass er „das Bekannte“ und die geläufigen und überlieferten „Vorstellungen“, die gewesenen Richtungen, Philosophien, Poesien und Religionen zur Richtschnur und Quelle der Begriffsbewegung durch die Gestalten des Geistes hin zum absoluten Wissen nimmt.

Diese Vergangenheit durchläufft das Individuum, dessen Substanz der höherstehende Geist ist, auf die Art, wie der eine höhere Wissenschaft vornimmt, die Vorbeitungskenntnisse, die er längst inne hat, um sich ihren Inhalt gegenwärtig zu machen, durchgeht; er rufft die Erinnerung derselben zurück, ohne darin sein Interesse und Verweilen zu haben. So durchlaufft jeder einzelne die Bildungsstuffen des allgemeinen Geistes, aber als vom Geiste schon abgelegte Gestalten, als Stuffen eines Wegs, der ausgearbeitet und geebnet ist; wie wir in Ansehung der Kenntnisse das, was in frühern Zeitaltern den reifen Geist der Männer beschäfftigte, zu Kenntnissen, Uebungen und selbst Spielen des Knabensalters herabgesunken sehen und in dem pädagogischen Fortschreiten die wie im Schattenrisse nachgezeichnete Geschichte der Bildung der Welt erkennen werden [das ist es also, was den Leser im nachfolgenden Buche erwartet]. (GW 24,23-25,2; ThW 32)

Die Wissenschaft stellt diese bildende Bewegung sowohl in ihrer Ausführlichkeit und Nothwendigkeit als das, was schon zum Momente und Eigenthum des Geists herabgesunken ist, in seiner Gestaltung dar. Das Ziel ist die Einsicht des Geistes in das, was das Wissen ist. (GW 25,14-17; ThW 33)

Als zweites Argument lässt sich ins Feld führen, dass auch noch der späte Schelling denselben Zug an Hegels Logik scharf kritisiert:

Hegeln schwebte bei seiner Logik nichts anderes als diese [altscholastische] Ontologie vor, die er über die schlechte Form erheben wollte, die sie z. B. in der Wolffischen Philosophie gehabt hatte, wo die verschiedenen Kategorien in einem mehr oder weniger bloß zufälligen, mehr oder weniger gleichgültigen Nacheinander aufgestellt und abgehandelt wurden. [...] In Hegels Logik findet man alle gerade zu seiner Zeit gangbaren und einmal vorhandenen Begriffe, jeden als Moment der absoluten Idee an einer bestimmten Stelle aufgenommen. Es ist damit die Prätension einer vollendeten Systematisierung, d.h. der Anspruch verbunden, daß alle Begriffe umfaßt, und außer dem Kreis der umfaßten kein anderer möglich sei. Wenn sich nun aber Begriffe aufzeigen ließen, von denen dieses System nichts weiß, oder die es nur in einem ganz anderen als dem echten Sinn in sich aufzunehmen wußte? (X, 138f.)

Mit Blick auf diese spätere Kritik wird auch klar, worauf Schelling in der Freiheitsschrift mit der Bemerkung anspielt, dass die Überlieferung „,bei einem gleichen Resultat schon früher" einmal zur Quelle und Richtschnur genommen worden sei. Er scheint nämlich damit auf den für seinen und Hegels Idealismus schlechthin zündenden Vorgang Kants hinzuweisen, der in seiner Kritik der reinen Vernunft Aristoteles dafür kritisierte, kein anderes als rhapsodistisches Prinzip für die Zusammenstellung 
der Kategorien gehabt zu haben, obwohl auch er selbst die Formen des Urteils nur mehr oder weniger aus der Überlieferung aufgriff, um dadurch die systematisch Einheit und Vollständigkeit seiner Kategorientafel darzutun. So wäre denn Hegel in der Phänomenologie von ihrer beider ursprünglichem Anliegen, die Kategorien des Wirklichen als ein System zu begründen, vorerst abgewichen. ${ }^{28}$

Die bisher artikulierte Kritik Schellings läßt sich, wenn sie auf Hegel bezogen wird, zusammenfassen als eine Kritik an Hegels Grundverständnis von philosophischer Wissenschaft: sie sei ihm in der bisher absehbaren Gestalt zu einem rein negativ bleibenden, verschiedene geschichtliche Stationen und Begriffe des Denkens dem dialektischen Taumel aussetzenden Unternehmen geraten ohne klar ersichtliche Richtung zu einem positiven Ziel; und sie bewege sich deshalb auch ohne erzeugende und organisch gestaltende Kraft höchstens am Leitfaden historischer Zufälligkeiten fort.

\section{Die Antizipation des Subjekts und seine fingierte Geschichte}

Wenn ich die Freiheitsschrift einigermaßen kühn als Schellings Phänomenologie des Geistes bezeichnet habe, so tue ich das nicht nur mit Berufung darauf, daß in ihr das Schellingsche Prinzip des philosophischen Wissens erst am Ende zum einnehmbaren Standpunkt geworden ist, als gleichsam getragen von der vorausentworfenen Entwicklungsskizze des Geistes durch die Natur- und Menschheitsgeschichte hindurch. Vielmehr zeigt sich in der Freiheitsschrift erstmals eine höchst interessante Konzeption von Schellingscher Systemphilosophie als Philosophie des Absoluten, die einerseits deutlich an gewissen Vorgaben Hegels in der Vorrede Maß nimmt, andererseits aber mit eigenen Zutaten Schellings ${ }^{29}$ fast den ganzen Rest seines philosophischen Schaffens

28 Dies bezöge sich zunächst natürlich nur auf den bis dato publizierten ersten Schritt von Hegels systematischer Philosophie; allerdings scheint Schelling, wie das vorangegangene Zitat zeigt, dieses Urteil auch angesichts der später publizierten Logik und der Enzyklopädie Hegels nicht revidiert zu haben.

29 Die Zutaten sind allerdings so erheblich, dass sie hier nur angedeutet, aber nicht vollständig aufgelistet werden können. Zu den wichtigsten gehört, dass der gesamte Entwicklungsprozess (das „System der Weltalter") als transzendentale Vergangenheit zugleich des Gottesbegriffs und der Schöpfung sowie auch des menschlichen Bewusstseins und der Prinzipien möglichen Wissens aufgefasst wird, die mit dem Ziel einer dadurch erst gestifteten, positiven Gegenwart des letzteren (des Bewusstseins im Verhältnis zur Wirklichkeit Gottes) vergewissert werden soll. Der theologische Rahmen und die zeittheoretischen Erwägungen 
bestimmt hat und in dieser Form von Schelling mindestens an einer Stelle seines Werks als „Phänomenologie des Geistes“ betitelt wurde. ${ }^{30}$

Zunächst möchte ich die systematische Anknüpfung an Hegels Vorrede deutlich machen. Hegel fasste dort die Entwicklung eines absoluten Systems mithilfe seiner Theorie des spekulativen Satzes auf als die "Antizipation" eines Subjektes, dessen Identität sich erst am Ende des Satzes, nämlich in den von ihm ausgesagten Prädikaten enthüllt, die aber andererseits jene Antizipation des Subjekts sozusagen wieder rückgängig machen und es endgültig in sich ziehen, d.h. aufheben müssten.

Das Bedürfniß, das Absolute als Subject vorzustellen, bediente sich der Sätze: Gott ist das Ewige, oder die moralische Weltordnung oder die Liebe usf. In solchen Sätzen ist das Wahre nur geradezu als Subject gesetzt, nicht aber als die Bewegung des sich in sich selbst Reflectirens dargestellt. Es wird in einem Satze der Art mit dem Worte: Gott, angefangen. Diß ist für sich ein sinnloser Laut, ein blosser Nahme; erst das Prädicat sagt, was er ist, ist seine Erfüllung und Bedeutung; der leere Anfang wird nur in diesem Ende ein wirkliches Wissen. (GW 20,26-32; ThW 26f.)

Hierzu ist zu bemerken, dass Schelling, wenn man es im Groben beschreibt, ganz ähnlich verfährt. Am Anfang der Untersuchung in der Freiheitsschrift steht ein gewisses Subjekt, das ,Gott' genannt wird, und dies und jenes tut. Was es tut, entwickelt sich dahin, dass am Ende die Liebe und Indifferenz, welche uns - die Wissenden - enthält, als dasjenige herausgestellt wird, was schon am Anfang jenen Namen trug. Doch ist das noch nicht alles, sondern das Entscheidende kommt erst. Hegel fährt nämlich fort:

Insofern ist nicht abzusehen, warum nicht vom Ewigen, der moralischen Weltordnung usf. [also von jenen Prädikaten] oder, wie die Alten thaten, von reinen Begriffen, dem Seyn, dem Einen usf. von dem, was die Bedeutung ist, allein gesprochen wird, ohne den sinnlosen Laut noch hinzuzufügen. Aber durch diß Wort wird eben bezeichnet, daß nicht ein Seyn oder Wesen oder Allgemeines überhaupt, sondern ein in sich reflectirtes, ein Subject gesetzt ist. (GW 21,1-6; ThW 27)

Danach gebraucht man also den Namen ,Gott', um auszudrücken, dass man ein Individuum meint, das für sich existiert und Selbstbewußtsein besitzt. Genau dies ist offenkundig auch Schellings Absicht, wenn er sagt, dass Gott entsprechend der Sehnsucht sich reflektiere und mit seiner eigenen Reflexion zum Geist vereinige, der wiederum das Schaffenswort ausspreche in die Welt, damit nun eine Wiedergeburt

sind dabei Elemente, die der Hegelschen Systematik eher fern liegen. Von Hegel geborgt ist nur die Idee, dass die Gewissheit der Prinzipien des spekulativen Systems erst an einem Ende der Gedankenentwicklung herausgestellt und erhärtet, nicht aber an ihrem Anfang schon vorausgesetzt werden kann.

30 Vgl. unten Abschnitt 6. 
des Geistes in endlicher Form ihren Anfang nehmen kann. ${ }^{31}$ Doch sehen wir weiter im Text Hegels, der nun eine Peripetie beschreibt:

„Allein zugleich ist dies nur anticipirt“ (GW 21,6; ThW 27). Das soll bedeuten: Es ist ja noch gar nicht durch die Gedankenführung gedeckt, daß es sich bei ,Gott' um ein denkendes, handelndes, in sich reflektiertes und sich offenbar machendes Individuum, d.h. um eben ein Subjekt handelt. Daher gilt vorläufig:

Das Subject ist als fester Punkt angenommen, an den als ihren Halt die Prädicate geheftet sind, durch eine Bewegung, die dem von ihm Wissenden angehört und die auch nicht dafür angesehen wird, dem Punkte selbst anzugehören; durch sie aber wäre allein der Inhalt als Subject dargestellt. (GW 21,6-10; ThW 27)

Der Wissende also, d.i. der, der den Satz formuliert, welcher mit jenem Subjekt beginnt, , leiht ${ }^{`}$ vorerst dem, was er meint, nur seine eigene Reflexionsbewegung, die zu den Prädikaten erst hinführt, die er davon meint aussagen zu können. Er macht dabei gewissermaßen sich selbst zu dem, was die Prädikate haben soll. - Ähnlich Schelling in der Freiheitsschrift, indem er alles tut, um das Wesen Gottes bei Erschaffung der Welt und Wiedererhebung des Geistes aus ihr „menschlich“ aussehen zu lassen, obwohl die dabei gebrauchten Prädikate und die beschriebene Entwicklungsbewegung nicht auf Gott selbst zutreffen können. ${ }^{32}$ Bei Hegel geht es in diesem Sinne konsequent weiter:

In der Art, wie diese Bewegung [des Wissenden zu den Zielprädikaten] beschaffen ist, kann sie ihm [dem Subjekt] nicht angehören; aber nach Voraussetzung jenes Punkts kann sie auch nicht anders beschaffen, kann sie nur äusserlich seyn. (GW 21,10-12; ThW 27)

So ist es auch bei Schelling; denn das ganze Werden des Geistes, das er ausgehend von Gottes Schöpfungsakt schildert, ist, wie er sagt, nicht Gott selbst zuzurechnen ${ }^{33}$,

31 Vgl. Freiheitsschrift SW VII, 360f. Bu 33,12ff.

32 So ist bspw. die Kennzeichnung des Entwicklungsgrundes in Gott als „Sehnsucht" nach Schelling ausdrücklich eine vom menschlichen Subjekt her geborgte Redeweise (s. SW VII, 359; Bu 31,34f.) und auch die ganze Rede von einer Entwicklung oder einem Werden Gottes ist nur ein aus unserer endlichen Betrachtungsweise geborgtes Moment (SW VII, 358f. Bu 31,13-19; vgl. SW VII, 403; $\mathrm{Bu} 75,20-22)$; vgl. auch die folgende Fn.

33 Dies wurde von den Interpreten der Freiheitsschrift gern übersehen; vgl. z.B.: ,[D]er Begriff des Werdens [ist] der einzige der Natur der Dinge angemessene [...]. Aber sie können nicht werden in Gott, absolut betrachtet, indem sie toto genere, oder richtiger zu reden, unendlich von ihm verschieden sind" (SW VII, 358f. Bu 31,16ff.) mit SW VII, 403; Bu 75,14ff.: ,[W]arum ist das Vollkommene nicht gleich von Anfang? Es gibt darauf keine Antwort als die schon gegebene: Weil Gott ein Leben ist, nicht bloß ein Sein. Alles Leben aber hat ein Schicksal und ist dem Leiden und Werden untertan. [...] Das Sein wird sich nur im Werden empfindlich. Im Sein freilich ist kein Werden; in diesem vielmehr ist es selber wieder als Ewigkeit gesetzt; aber in der Verwirklichung durch Gegensatz ist notwendig ein Werden." Ein Werden im strikten Sinne ist demnach nur in der „Verwirklichung" nach außen, d.h. in der Schöpfung und Offenbarung, hingegen ist das- 
der vorderhand also noch nicht weiter durch das Gesagte erfaßt und beschrieben wird. Mit dem nun folgenden abschließenden Satz Hegels trennen sich allerdings die Gedankengänge von Schelling und Hegel, indem Hegel glaubt eine bestimmte Konsequenz ziehen zu können - die jedoch keineswegs zwingend ist - während Schelling die gegenteilige Konsequenz zieht:

Jene Anticipation, daß das Absolute Subject ist, ist daher nicht nur nicht die Wirklichkeit dieses Begriffs, sondern macht sie sogar unmöglich, denn jene [Antizipation] setzt ihn als ruhenden Punkt, diese [die Wirklichkeit] aber ist die Selbstbewegung. (GW 21,12-15; ThW 27)

Schelling zieht, wie gesagt, hieraus die andere mögliche Konsequenz, nämlich daß die Selbstbewegung des Wissenden gar keine echte Bewegung, sondern nur ,illusorisch“ war (wie er spät einmal schreibt: SW X, 125). Sie war also die Selbstvorspiegelung von etwas, dessen Wirklichkeit nur angenommen, aber nicht behauptet wurde, sondern das nur dazu diente, um den nach philosophischer Wissenschaft Strebenden (den all das Dargelegte von Gott und seiner Schöpfung Prädizierenden) in eine Einheit und Innigkeit mit jenem als ruhend antizipierten Subjekt zu bringen.

Tatsächlich versteht Schelling die Funktion der Freiheitsschrift, wie schon im letzten Abschnitt deutlich wurde, in dieser Weise. Nämlich so, dass wir erst an ihrem Ende ein Recht und die Möglichkeit besitzen, uns in einer Indifferenz, d.h. Ununterschiedenheit mit jenem Subjekt zu denken, das wir für das Höchste oder Absolute halten. Dies jedoch wiederum nur gesetzt den Fall, es gebe wirklich eine solche Geschichte, wie sie die Freiheitsschrift erzählt. Ob es sie freilich gibt, diese Geschichte, das wissen wir nicht, sagt Schelling in einem späteren Text, auf den ich gleich noch genauer eingehen werde, sondern das ,wurde angenommen zum Behufe der Wissenschaft" 34 .

Wir können also erneut zusammenfassend sagen, dass Schelling in der Freiheitsschrift nach dem Modell des spekulativen Satzes aus Hegels Vorrede verfährt: Gott wird antizipiert als Subjekt und Stifter aller Wirklichkeit, die anschließend in Gestalt einer Entwicklungsbewegung des Geistes den dies Denkenden oder den Gott wissen Wollenden einholt und mit jenem Subjekt in eins setzt, d.h. identifiziert. Da aber Gott das ewig ruhende Subjekt ist, muss jene Bewegung zu uns selbst als Geist eine bloß zielführend (nämlich zum Wissen zielführend) angenommene oder bloß erscheinende Bewegung sein - d.h. eine Phänomenologie des Geistes.

selbe Werden qua „Ewigkeit“ noch einmal als Schöpfungsplan o. ä. in Gottes Verstand gesetzt.

34 Schelling 1995, 53 (s.u.) 


\section{Phänomenologie des Geistes und freiwillige Selbstoffenbarung}

Der schon angekündigte Text, in dem Schelling selbst die so erklärte Gedankenbewegung der Freiheitsschrift (allerdings ohne den Titel zu nennen) als „Phänomenologie des Geistes" bezeichnet hat, ist die Münchner Vorlesung System der Weltalter von 1827/28, die in einer von Ernst von Lasaulx kopierten Nachschrift durch Siegbert Peetz herausgegeben wurde. ${ }^{35}$ Die ungefähre Zeit, in die jene Gedankenentwicklung Schellings fiel, wird dadurch bestimmt, dass Schelling sie deutlich als die Nachfolgekonzeption zu seiner Identitäts- und Naturphilosophie markiert. Der Titel der Freiheitsschrift wird an dieser Stelle - wie meistens in der Rückschau Schellings - nicht genannt; und zwar wohl deshalb nicht, weil es eben die Systemkonzeption ist, die ihn bis ins hohe Alter beschäftigt, d.h. der Beginn seiner während der Zeit der Rückschau immer noch aktuellen Philosophie.

Die Überlegung, von der Schelling dort berichtet, geht aus von dem bekannten „Subjekt-Objekt“" als Prinzip der Identitätsphilosophie, das pantheistisch auch als die ,allgemeine Substanz" bezeichnet wird. Dies entspräche also in etwa dem Startpunkt der Einleitung in die Freiheitsschrift. Dazu führt nun Schelling in jener Vorlesung aus:

Nicht unbedingt ist jene allgemeine Substanz Gott zu nennen, sondern nur die sich selbst werdende, nur sich selbst seiende. (Schelling 1995, 52)

Also diejenige, so ist erklärend hinzuzufügen, die sich als ein Selbst unterscheidet von allem anderen, d.h. die ,sich persönlich macht" ${ }^{* 36}$; denn das erfordert, wie Schelling in der Freiheitsschrift erklärt, ,eine Bedingung“337.

Gott [aber] kann nicht mit dem Sein befangen sein, welches immer nur ein anderswerdendes ist. [...] Also konnte Gott kein sich Entfremdendes werden. (Schelling $1995,52)$

35 Der Text von Lasaulx ist keine direkte Nachschrift der Vorlesung Schellings, sondern die außerordentlich sorgfältige Abschrift einer sehr guten, d.h. den mündlichen Vortrag Schellings praktisch vollständig wiedergebenden, aber bislang nicht identifizierten Nachschrift eines Hörers. Diese Nachschrift kann nach dem Urteil des Herausgebers nicht identisch mit derjenigen sein, die sich im Privatbesitz von Horst Fuhrmans befand (heute Bayerische Staatsbibliothek cgm 8541), und aus der die Münchner Dissertation von Anton Mirko Koktanek von 1959 bereits erhebliche Passagen zitierte, die Peetz mit dem Lasaulxschen Text verglichen und bei Abweichungen in Konkordanz mit dem von ihm herausgegebenen Text (vgl. 217-222) publiziert hat.

36 Vgl. Freiheitsschrift SW VII, 395; Bu 67,10

37 Vgl. Freiheitsschrift, z. B. SW VII, 399; Bu 70,34ff.; SW VII, 403; Bu 74,20-24. 
Hier bekräftigt Schelling offensichtlich, dass die damals aufgebrachte Grundidee Hegels für ihn ausschied: Es kann nach seiner Ansicht nicht das Absolute selbst sein, das sich in eine sich von ihm selbst entfremdende Bewegung begibt.

Zwar könnte man das Verhältnis der sich gleich bleibenden und sich entfremdenden Substanz so bestimmen, daß man diese [die sich entfremdende] als nur zur Form der Existenz Gottes, nicht zum Wesen gehörend betrachtete, so daß nur dieses ewig in sich seiende Wesen von dieser Form der Endlichkeit getragen würde. (Schelling 1995, 52)

Diese Denkmöglichkeit bezeichnet in etwa die Systemkonzeption, die Schelling früher bevorzugt hatte, z. B. in den Ferneren Darstellungen oder in Philosophie und Religion, sogar noch in der Darlegung gegen Fichte, wo jeweils alles Differente und für sich genommen Endliche die Form der Existenz des absoluten Wesens, der Einheit oder des „Bandes“ ausmachen sollte. Aber das genügt ihm jetzt nicht mehr, und genügte ihm auch in der Freiheitsschrift erstmals nicht aus folgendem Grund:

[...] allein dieses, eine Form der Existenz Gottes konnte es nur sein, wenn es eine freiwillige Selbstoffenbarung war. Nun frägt es sich: Ob diese Existenz eine freiwillige sich-selbst-Offenbarung war: dann wäre diese Existenz eine gewordene. (Schelling 1995, 52)

Diese Schwierigkeit hatte immer Jacobi gegen Schellings Identitätssystem eingewendet: alle Freiwilligkeit des göttlichen Schöpfungshandelns werde nämlich dadurch vertan, dass Gott nicht eine von der Offenbarung in den Dingen unabhängige Existenz zugesprochen werden könne. In der Freiheitsschrift hatte Schelling dies nun anders machen wollen und die Freiwilligkeit behauptet. ${ }^{38}$ Den Preis dafür nennt er in einem Atemzug: dass dann diese Existenz eine einst gewordene, nicht ewig mit dem Wesen gegebene sein müßte. Dies bedeutet natürlich wiederum, wie schon weiter oben hervorgehoben, dass sie nicht mehr die Existenz des Absoluten selbst sein kann. Schelling erklärt nun die Vorzüge einer solchen gewordenen Offenbarung oder veräußerten Existenz unter dem Stichwort „Geschichtlichkeit“:

In diesem Falle hätte sich dann die Form der Geschichtlichkeit als eine wirkliche, gewordene aufzeigen lassen. Nur in dem freiwilligen Sichselbstsetzen, nur in der Geschichtlichkeit laßen sich die endlichen Formen wieder allmäliger als sich selbst offenbarend, begreiflich erkennen. (Schelling 1995, 52)

Die Freiwilligkeit Gottes überträgt sich also auf die Freiwilligkeit des Endlichen, mit dessen Hervorbringung sich Gott zu offenbaren beginnt. Das Problem ist nur, daß das so allmählich werdende Endliche

38 In der Darlegung dagegen wird die „Selbstoffenbarung“ des Absoluten ausdrücklich eine „,notwendige“" genannt (vgl. Fn. 17). 
eben nicht mehr die Existenz Gottes sein kann, sondern bloß die des Endlichen ist, und daß sich deshalb auch nicht mehr ohne weiteres Gott als existierend darin offenbart. Daraus zieht Schelling nun die entscheidende Folgerung:

Also keineswegs dieses nur sich, sondern ein anderes sezendes Subject konnte eine freiwillige Offenbarung des Höchsten sein. (Schelling 1995, 52)

Wenn also das allsetzende Subjekt, mit dem wir begannen, der freiwillig setzende und sich offenbarende Gott ist, dann offenbart er sich nicht, indem er nur sich setzt, sondern indem er ein anderes setzt, das ihn freiwillig offenbart. Die Schwierigkeit, die bei dieser Konzeption übrig bleibt, ist allerdings die, daß das Gott freiwillig offenbarende andereals-Gott nicht anders als geschichtlich und geworden und deshalb nicht unmittelbar, sondern erst in der Vollendung eins mit Gott selbst sein kann.

Es war also unmöglich das nothwendige Sein Gottes als ein Werden zu begreifen, und weil dieses unmöglich war, so war es nothwendig dieses [das Werden] in einer zum Behufe der Wissenschaft ${ }^{39}$ angenommenen Geschichtlichkeit (Phänomenologie des Geistes) ${ }^{40}$ darzustellen. [...] Allein weil diese Geschichtlichkeit nur angenommen, nicht wirklich war, so mußte sie bei dem lezten Gedanken wieder aufgegeben werden. Sie war nur angenommen, der höchste Gedanke mußte sie wieder vernichten und es war wieder ein logisches Verhältniß eingetreten, wie dieses auch Hegel, nur nach seiner Art undeutlich, ausdrückt: [es folgt ein Hegelzitat aus der Encyklopädie § 465]. (Schelling 1995, 52f.)

Mit seinen letzten Bemerkungen übt Schelling wiederum deutliche Kritik an der für seine Ansprüche an eine freiwillige Selbstoffenbarung des Absoluten auch in der Freiheitsschrift noch ungenügenden Systementwicklung. Denn sie habe am Ende den geschichtlichen Entwicklungsgedanken durch ein logisches Verhältnis ersetzen müssen, um zu ihrem Ziel zu kommen. Dass die Freiheitsschrift so in der Tat endete, ist klar: der Gedanke der Indifferenz und ihr Verhältnis zur Dualität der Prinzipien ist ein rein logisches Konstrukt, das mit dem Vorangehenden nur lose über die Glei-

39 Das in der Münchner Universitätsbibliothek erhaltene Originalmanuskript Schellings (das allerdings recht lückenhaft und z.T. nur stichpunktartig ist) zur selben Vorlesung (4 Cod. ms. 1000) hat an dieser Stelle (moderne Blattzählung 120 unten): ,zum Behufe der Constr $<$ uction $>$ oder wiss $<$ enschaftlichen $>$ Entwicklung“, wobei „Constr. oder" gestrichen ist.

40 Die in Klammern eingefügte Bemerkung war mit großer Sicherheit ein Bestandteil des mündlichen Vortrags von Schelling, obwohl sie im erhaltenen Originalmanuskript Schellings (vgl. Fn. 39) nicht zu finden ist. Denn die in Fn. 35 erwähnte, wahrscheinlich unabhängige Nachschrift eines unbekannten Hörers (Bayerische Staatsbibliothek cgm 8541) zeigt an dieser Stelle (pag. 102) genau denselben Textbefund. 
chung zwischen Indifferenz und Liebe verbunden ist. ${ }^{41}$ Warum aber war das nötig? Warum konnte die gegebene geschichtliche Bewegung nicht als eine solche zum Ziel des absoluten Wissens führen?

Deshalb, weil nur dann, wenn wir uns hätten vergewissern können, dass die freiwillige Offenbarung des endlichen Geistes keine andere ist als die freiwillige Selbstoffenbarung des unendlichen Geistes Gottes, die „zu ihrem Behufe" angenommene Geschichtlichkeit, welche die Freiheitsschrift darstellt, eben die wirkliche und echte Geschichte des Geistes wäre. Doch konnten wir uns der geforderten Identität nicht vergewissern, weil alle mögliche Gewißheit davon in unserer Zukunft lag. Haben wir aber diese Gewißheit nicht, so ist auch die ganze Vergangenheit davon, so wie sie dargestellt wurde, eine bloße Fiktion, die als Fiktion nicht uns Geschichtliche an den gewünschten Ort des absoluten Wissens bringt. Es ist also letztlich die geforderte Freiwilligkeit verbunden mit der Weigerung Schellings, Gott oder den absoluten Geist selbst einem Werden unterworfen zu denken, welche einen Keil treibt zwischen uns als wirklich und geschichtlich existierende Individuen und allem, was wir als notwendige Verfassung irgendeines absoluten Wesens einsehen können, auch wenn wir noch so viele Geschichten erfinden können, die das wirklich Existierende mit dem notwendig so und so Verfassten irgendwie verbinden. Diese Einsicht hatte Schelling jedoch in der Freiheitsschrift noch nicht, sondern damals hielt er seine Phänomenologie des Geistes für eine vorerst zufriedenstellende Lösung des Problems.

\section{Das Andere in der Selbstoffenbarung}

Doch soll am Schluss außer auf die Selbstkritik Schellings noch einmal der Blick auf ein mögliches Stück der Kritik Schellings an Hegels Philosophie zur Zeit der Freiheitsschrift gelenkt werden. Ein gesicherter Ertrag der konzeptionellen Überlegungen Schellings zu dieser Zeit ist, wie wir gesehen haben, die Tatsache, dass nur ein radikal anderes Subjekt als Gott selbst das Gott offenbarende Subjekt sein kann. Die Freiheitsschrift behauptete diese These so:

Wäre nun im Geist des Menschen die Identität beider Prinzipien ebenso unauflöslich als in Gott, so wäre kein Unterschied, d.h. Gott als Geist würde nicht offenbar. Diejenige Einheit, die in Gott unzertrennlich ist, muß also im Menschen zertrennlich sein, - und dieses ist die Möglichkeit des Guten und des Bösen. (SW VII, 364; Bu 36,18ff.)

41 Vgl. oben Fn. 22. 
Für Schelling bedeutet dies schon seit seiner Schrift gegen Fichte, die er Hegel zugeschickt hatte, und darüber hinaus in der gesamten an die Freiheitsschrift sich anschließenden Philosophie, dass Gott oder das Absolute - wer oder was immer es sei und wie es sich auch setze oder offenbare - jedenfalls an sich selbst und ursprünglich die Verbindung von sich selbst und einem anderen gewesen sein muß.42 Diese interne Verschiedenheit bleibt auch erhalten in all seinem ferneren Selbstsetzen und Tätigsein, und das ist jener wichtige Punkt für die freiwillige Selbstoffenbarung Gottes, auf den Schelling im System der Weltalter direkt hinweist: dass wir eines darin haben, das er selbst ist und das ungerührt und unberührbar von der Bewegung und geschichtlichen Entwicklung bleibt; und ein anderes, das - ursprünglich in völliger Deckung und Einigkeit mit ihm - es übernimmt, ihn durch die Bewegung freiwillig offenbar zu machen. ${ }^{43}$ Dies andere ist nach dem Schöpfungsakt der endliche Mensch, der jedenfalls - wenn ihm doch die Aufgabe zufällt, Gott offenbar oder das Absolute über sich hinaus bewußt zu machen - ein anderer sein muss als Gott oder das Absolute.

Eine derartige Verschiedenheit zwischen Gott und Mensch möchte Schelling auf jeden Fall festgehalten wissen, und er begründet sie, wie gesehen, durch ein eigenes Argument erstmals in der Freiheitsschrift. Ob dies mit kritischem Blick auf Hegel geschah, ist schwer zu beurteilen. Doch erscheint es nicht als ausgeschlossen, da Hegel seinerseits zwar keine explizite Gleichsetzung beider als Formen des Geistes vornimmt, jedoch auch keine deutlich argumentierende Abgrenzung aufrecht erhält. Vielmehr geht in der Bewegung des Begriffs auch die Menschwerdung Gottes in Christus schließlich über in das Selbstbewußtsein des Geistes in uns, so dass hier Grenzen verwischt werden, die Schelling jedenfalls einer entschiedenen Bekräftigung für bedürftig hält. Das führt bei Hegel am Ende auf Tonlagen in der Diktion des reinen Begriffs, die den früheren Schellings - von denen Hegel so grobschlächtig Abstand genommen hatte - ähnlicher sind als der spätere Schelling, also der, der von Hegel gelernt hat, sie jemals noch hervorbringen wollte:

[D]ieser Gott wird unmittelbar als Selbst, als ein wirklicher einzelner Mensch, sinnlich angeschaut; so nur ist er Selbstbewußtseyn. Diese Menschwerdung des göttlichen Wesens, oder daß es wesentlich und unmittelbar die Gestalt des Selbstbewußtseyns hat, ist der einfache Inhalt der absoluten Religion. In ihr wird das

42 Vgl. Fn. 17.

43 Vgl. Schelling 1969, 150: „Nicht Gott selbst wird ein seiendes, er wird nicht seiend dadurch, daß er etwas wird, sondern dadurch, daß das andere etwas wird. Nur dadurch wird Gott Gott, daß das, was ihm gleich war, aber mit der Möglichkeit, ihm ungleich zu werden, ihm wirklich ungleich wird, damit er in seiner Lauterkeit und Blosheit sich darstelle. Nicht Gott selbst wird ein Seiendes; er bleibt in sich selbst die ewige Freiheit zu sein: absoluter Geist.“ 
Wesen als Geist gewußt, oder sie ist sein Bewußtseyn über sich, Geist zu seyn. Denn der Geist ist das Wissen seiner selbst in seiner Entäusserung; das Wesen, das die Bewegung ist, in seinem Andersseyn die Gleichheit mit sich selbst zu behalten. [...] In dieser Religion ist deßwegen das göttliche Wesen geoffenbart. [...] Er wird gewußt als Selbstbewußtseyn und ist diesem unmittelbar offenbar, denn er ist dieses selbst; die göttliche Natur ist dasselbe, was die menschliche ist, und diese Einheit ist es, die angeschaut wird. ${ }^{44}$

Wer hätte mit einer derartigen Umkehrung der Auffassungen zwischen Schelling und Hegel, d.h. mit einem solchen Einmünden Hegels in die aktuell gegebene und ihrer selbst gewisse Anschauung des Absoluten nach den harschen Worten gegen Schelling in der ,Vorrede ${ }^{6}$ - noch gerechnet? Die Aufnahme von Hegels Kritik hat Schelling in Beziehung auf eine Wissenschaft vom Absoluten skeptischer hinterlassen, als sein Kritiker je gewesen ist. Von dieser Skepsis hat Schelling sich bis zum Ende seines Philosophierens nicht mehr trennen wollen.

Bonsiepen, W. 1981. „Zu Hegels Auseinandersetzung mit Schellings Naturphilosophie in der ,Phänomenologie des Geistes“". In Schelling. Seine Bedeutung für eine Philosophie der Natur und der Geschichte. Ed. L. Hasler. Stuttgart-Bad-Cannstatt: 167-172.

Düsing, K. 1977. „Spekulative Logik und positive Philosophie. Thesen zur Auseinandersetzung des späten Schelling mit Hegel“. Hegel-Studien, Beiheft 17: 117-128.

Ehrhardt, W.E. 1992. „Schellings letzte Kritik an Hegel zu dessen Lebzeiten“. HegelJahrbuch: 11-16.

-. 1995. „Das Ende der Offenbarung (403-416)“. In Schelling: Über das Wesen der menschlichen Freiheit. Ed. O. Höffe/A. Pieper. Berlin: 221-234.

Jacobi, F. 1968. „Über gelehrte Gesellschaften, ihren Geist und Zweck“. Werke, Bd. VI. Ed. F. Roth/ F. Köppen. Repr. Darmstadt.

Jacobs, W.G. 1998. „Schelling im Deutschen Idealismus. Interaktionen und Kontroversen“. In F. W. J. Schelling. Ed. H. J. Sandkühler. Stuttgart: 66-81.

Frank, M. 1998. „Schelling's Critique of Hegel“. Idealistic Studies 19: 251-268.

Fuhrmans, H. (ed.) 1962-1975. F.W.J. Schelling. Briefe und Dokumente, Band I-III. Bonn.

Hegel, G.W.F. 1979. Differenz des Fichteschen und Schellingschen Systems der Philosophie. Jenaer Kritische Schriften (I). Ed. H. Brockard/H. Buchner. Hamburg.

-. 1980. Phänomenologie des Geistes. Gesammelte Werke in Verbindung mit der Deutschen Forschungsgemeinschaft hrsg. von der Rheinisch-Westfälischen Akademie der Wissenschaften. Bd. 9. Ed. W. Bonsiepen/R. Heede. Hamburg (zitiert: GW).

44 Hegel, Phänomenologie GW 405,12-406,10; ThW 552f. 
-. 1970. Phänomenologie des Geistes. Theorie-Werkausgabe Bd. 3. Ed. E. Moldenhauer/K.M. Michel. Frankfurt a.M. (zitiert: ThW).

Hoffmeister, J. (ed.) 1952. Briefe von und an Hegel. Band I (1785-1812). Hamburg. Horstmann, R.-P. 1986. „Logifizierte Natur oder naturalisierte Logik. Bemerkungen zu Schellings Hegel-Kritik“. In Hegels Philosophie der Natur. Ed. R.-P. Horstmann/M.J. Petry. Stuttgart: 290-308.

Koktanek, A. M. 1959. Schellings erste Münchner Vorlesung 1827/28, System der Weltalter'. Dissertation München.

Krings, H. 1977. „Die Entfremdung zwischen Schelling und Hegel (1801-1807)“. Sitzungsberichte der Bayerischen Akademie der Wissenschaften. Philos.-Hist. Klasse: Jg. 1976, Heft 6.

Moiso, F. 1986. „Die Hegelsche Theorie der Physik und der Chemie in ihrer Beziehung zu Schellings Naturphilosophie“. In Hegels Philosophie der Natur. Ed. R.-P. Horstmann/M.J. Petry. Stuttgart: 54-87.

Schelling, F.W.J. von. 1856-61. Sämmtliche Werke. Ed. K.F.A. Schelling. Band IXIV, Stuttgart (zitiert: SW)

-. 1946. Die Weltalter. Fragmente. Ed. M. Schröter. München.

-. 1969. Initia Philosophiae Universae (Erlanger Vorlesung von 1820/21). Ed. H. Fuhrmans. Bonn.

-. 1989. Einleitung in die Philosophie. Ed. W.E. Ehrhardt. Stuttgart-Bad Cannstatt.

-. 1990. System der Weltalter. Ed. S. Peetz. Frankfurt a.M.

-. 1997. Philosophische Untersuchungen über das Wesen der menschlichen Freiheit und die damit zusammenhängenden Gegenstände. Hrsg. mit Einleitung und Anmerkungen von Th. Buchheim. Hamburg (zitiert: Bu).

Schlegel, F.W. 1975. Kritische Wilhelm-Schlegel-Ausgabe. Bd. VIII: Studien zur Philosophie und Theologie. Ed. E. Behler/U. Struc-Oppenberg. München, Paderborn, Wien.

Theunissen, M. 1977. „Die Idealismuskritik in Schellings Theorie der negativen Philosophie“. Hegel-Studien, Beiheft 17: 173-191. 